\title{
Classifications in Brief: Johnson and Strom Classification of Adult-acquired Flatfoot Deformity
}

\author{
Mostafa M. Abousayed MD, Jason P. Tartaglione MD, \\ Andrew J. Rosenbaum MD, John A. Dipreta MD
}

Received: 18 August 2015/Accepted: 30 September 2015/Published online: 15 October 2015

(C) The Association of Bone and Joint Surgeons \& 2015

\section{History}

Adult-acquired flatfoot deformity is characterized by collapse of the medial longitudinal arch (Fig. 1) with failure of the supporting posterior medial soft tissue structures of the ankle and hindfoot [26]. Although pes planus can be attributed to arthritic, developmental, neuromuscular diseases, and traumatic conditions $[1,2,4-6,11,15,18,21$, 26], posterior tibial tendon dysfunction remains the mostcommon etiology. Posterior tibial tendon dysfunction includes a wide spectrum of conditions affecting the tendon, with rupture, deformity, and secondary arthritis being among the more-severe sequelae. This condition has been estimated to affect approximately 5 million people in the United States [14].

In 1936, Kulowski was the first to describe posterior tibial tendinitis [18]. However, it was not before 1986 when Funk et al. [11] described the signs and symptoms associated with posterior tibial tendon rupture. From this work, the classic appearance of a valgus hindfoot and abducted forefoot was elucidated, as was the "too many toes" sign (Fig. 2), and the importance of a single-leg heel

Each author certifies that he or she has no commercial associations (eg, consultancies, stock ownership, equity interest, patent/licensing arrangements, etc) that might pose a conflict of interest in connection with the submitted article.

All ICMJE Conflict of Interest Forms for authors and Clinical Orthopaedics and Related Research ${ }^{\mathbb{B}}$ editors and board members are on file with the publication and can be viewed on request.

M. M. Abousayed ( $₫)$, J. P. Tartaglione, A. J. Rosenbaum, J. A. Dipreta

Division of Orthopaedic Surgery, Albany Medical College, 1367

Washington Avenue, Suite 202, Albany, NY 12206, USA

e-mail: mostafa.abousayed@gmail.com rise (Fig. 3) as an indicator of posterior tibial tendon dysfunction $[11,15,18,20]$.

The posterior tibial tendon functions mainly as a dynamic support of the medial arch. It also inverts the foot and aids in ankle plantar flexion. Dysfunction of the posterior tibial tendon usually manifests early with pain and swelling along the medial aspect of the foot and behind the medial malleolus. The pain is worse with prolonged standing and activities, and usually is associated with tenderness along the length of the tendon. In advanced posterior tibial tendon dysfunction, collapse of the medial arch occurs, leading to the characteristic pes planus deformity with hindfoot valgus; initially, this deformity is flexible, but in more-advanced stages it can become fixed and associated with forefoot abduction. The single-heel rise test can assess the function of the tendon, where varus alignment of the hind foot is indicative of a healthy tendon. Lateral-sided ankle pain occurs eventually in some patients, a result of subfibular impingement.

In 1989, Johnson and Strom created a three-stage posterior tibial tendon dysfunction classification system based on the condition of the posterior tibial tendon, the position of the hindfoot, and flexibility of the deformity [17]. Although a fourth stage in this system is commonly attributed to Myerson [24], this stage was described in the original article by Johnson and Strom [17]. It helps guide treatment in patients with deltoid ligament insufficiency and ankle joint involvement.

Better understanding of the biomechanics of the foot, particularly the medial arch and its supporting structures, has led to more precise understanding of the development of adult-acquired flatfoot deformity $[3-5,7,10,13,15,20$, 25, 27]. Although numerous authors have devised their own classification systems $[4,5,15,25]$, all used the original structure described by Johnson and Strom [17]. 

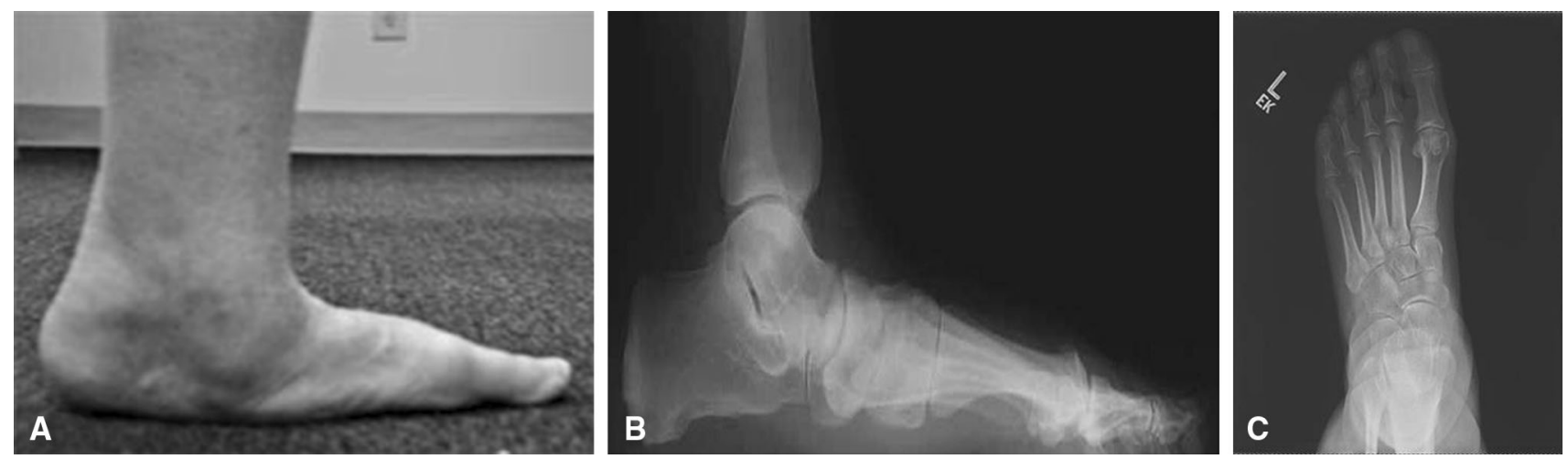

Fig. 1A-C (A) A photograph of a left foot shows pes planus with collapse of the medial longitudinal arch. (B) A lateral radiograph shows talonavicular collapse and decreased first tarsometatarsal angle, and (C) the AP radiograph shows talonavicular uncovering.

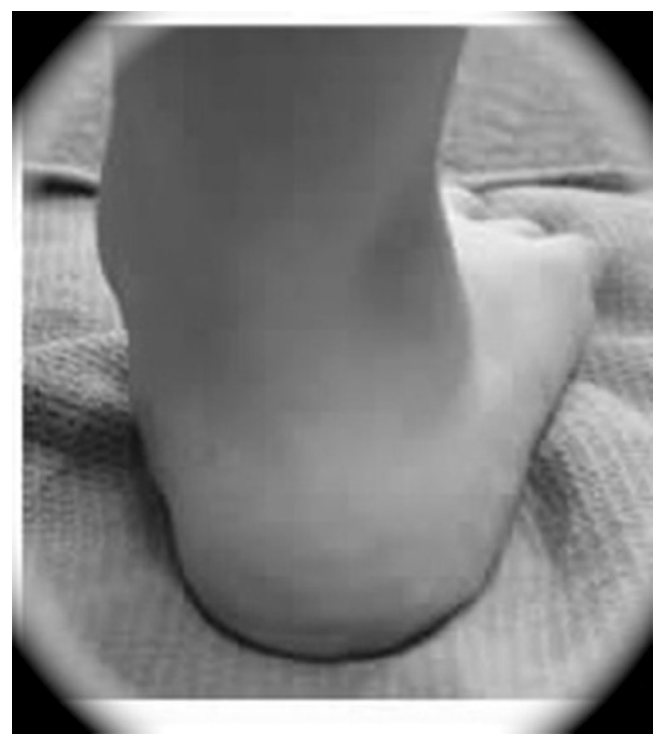

Fig. 2 A posterior view of a right foot shows a hindfoot valgus deformity with a concomitant abducted forefoot deformity, resulting in the "too many toes" sign.

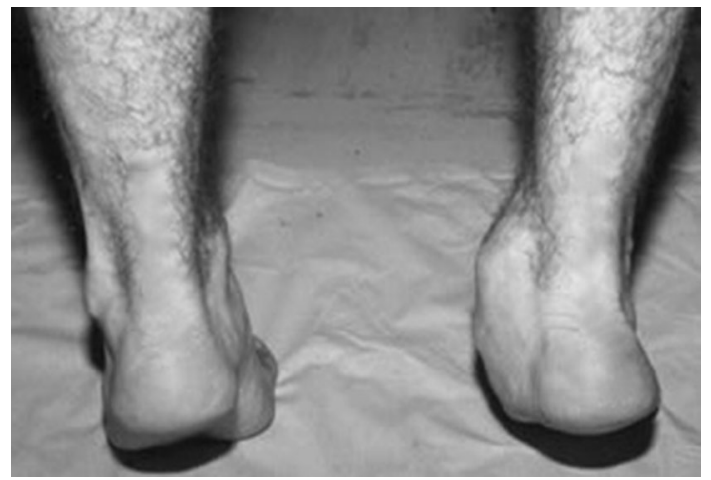

Fig. 3 A positive heel-rise test is shown in this photograph, which shows hindfoot valgus of the right side with underlying flatfoot deformity, in contrast to the varus alignment of a normal foot, which is shown on the left side.

\section{Purpose}

Historically, adult-acquired flatfoot deformity has been attributed to posterior tibial tendon dysfunction [16, 19]. Nevertheless, adult-acquired flatfoot deformity in its current form includes a wide range of deformities affecting the hindfoot, mid-foot, and the ankle. Although diagnosis of flat foot can be relatively easy, accurate identification of the different aspects of the deformity can be challenging. The Johnson and Strom classification is clinical and anatomic, and it was the first to look at flatfoot as a spectrum of deformities and guide treatment strategies. Similar to other classification systems, in addition to guiding treatment and facilitating communication among surgeons, it provides useful prognostic information. Many patients with milder forms of tendon dysfunction as graded by this classification system will respond to conservative measures, whereas more patients with more-severe forms of the condition will undergo surgical interventions to treat pain or disability $[4,5,8,18,24,27]$.

\section{Description}

In 1989, Kenneth A. Johnson and David E. Strom [17] described three stages of posterior tibial tendon dysfunction that later served as the most-commonly used classification system for adult-acquired flatfoot deformity (Table 1).

In Stage I of the disease, patients may report mild pain along the medial aspect of the ankle that is exacerbated by activities. On examination, swelling, fullness, and tenderness are localized to the course of the posterior tibial tendon. Tendon length is usually normal. Pathologic examination of the tendon will reveal synovial proliferation [23]. Other findings include paratendinitis, normal alignment, and mild weakness on single-heel rise test. No 
Table 1. Johnson and Strom classification

\begin{tabular}{|c|c|c|c|}
\hline Variable & $\begin{array}{l}\text { Stage I } \\
\text { Mild, medial pain }\end{array}$ & $\begin{array}{l}\text { Stage II } \\
\text { Moderate, medial pain }\end{array}$ & $\begin{array}{l}\text { Stage III } \\
\text { Severe, medial and lateral pain }\end{array}$ \\
\hline \multicolumn{4}{|l|}{ Examination } \\
\hline $\begin{array}{l}\text { Swelling and } \\
\text { tenderness }\end{array}$ & $\begin{array}{l}\text { Mild swelling and tenderness along } \\
\text { posterior tibial tendon }\end{array}$ & $\begin{array}{l}\text { Moderate swelling and tenderness along } \\
\text { posterior tibial tendon }\end{array}$ & $\begin{array}{l}\text { Not much swelling but marked tenderness } \\
\text { along posterior tibial tendon }\end{array}$ \\
\hline Heel-rise test & Mild weakness & Marked weakness & Marked weakness \\
\hline $\begin{array}{l}\text { "Too many } \\
\text { toes" sign }\end{array}$ & Absent & Present & Present \\
\hline Deformity & Absent & Present (flexible) & Present (fixed) \\
\hline $\begin{array}{r}\text { Pathologic } \\
\text { features }\end{array}$ & Normal tendon length, paratendinitis & Elongated with longitudinal tears & Disrupted with visible tears \\
\hline Images & No changes & Gross deformity & Deformity and diffuse arthritic changes \\
\hline Treatment & Conservative, tenosynovectomy & Flexor digitorum longus transfers & Triple arthrodesis \\
\hline
\end{tabular}

changes in bony architecture are expected on routine standing radiographic images. Treatment at this stage consists initially of conservative measures including rest, antiinflammatory agents, arch supports, and orthotics. Treatment is continued for 3 months, and if no improvement is noticed, tenosynovectomy and débridement or repair of tendon tears may be considered.

In Stage II, pain is moderate although usually more debilitating, and localized along a longer segment of the tendon. Swelling, fullness, and tenderness are more pronounced. There is elongation of the posterior tibial tendon, which results in the characteristic pes planus deformity. Pathologic examination shows degeneration with multiple longitudinal tears [23]. Single-heel rise test reveals marked weakness (Fig. 2). Visible deformity and malalignment of the hind foot are present, although mobile, and the "too many toes" sign can be seen (Fig. 3). Standing radiographs will show forefoot abduction in relation to the hindfoot and talonavicular subluxation. The surgical treatment we prefer for patients with Stage II deformity who elect to undergo surgery is flexor digitorum longus tendon transfers.

In Stage III, pain can be severe and may be evident on the lateral foot at the sinus tarsi in addition to the medial arch. There is severe elongation and disruption of the tendon. On examination, the swelling and fullness might be less evident but the deformity is more pronounced. On pathologic examination, the tendon is disrupted with visible tears [23]. Single-heel rise is painful and shows marked tendon weakness. Hindfoot eversion and forefoot abduction are present and the deformity usually is fixed. The "too many toes" sign is still present. The same changes as seen in Stage II on plain films can be appreciated in addition to degenerative arthritic changes in the subtalar, talonavicular, and calcaneocuboid joints. Treatment for patients presenting with Stage III pain may include subtalar arthrodesis.

Johnson and Strom [17] alluded to a possible Stage IV in which the fixed valgus deformity of the hindfoot results in lateral talar tilt in the ankle mortise. They suggested tibiotalocalcaneal fusion as a possible treatment for such deformity. Myerson [24] was credited for Stage IV modification of the original classification. He described valgus deformity of the ankle associated with deltoid ligament insufficiency, which sometimes can be associated with lateral tibiotalar arthritis. He further subdivided Stage IV into type A with flexible ankle deformity amenable to deltoid ligament reconstruction with triple arthrodesis or type B with fixed deformity and requiring pantalar arthrodesis.

Although the treatment modalities originally suggested by Johnson and Strom still are helpful, they are not-and need not be-consistently applied. For example, some surgeons may elect to prolong the period of conservative treatment longer than 3 months before considering surgical options. Additionally, newer methods of immobilization have been proposed, and some patients are not good surgical candidates, or opt not to have surgery. The same concerns apply to Stages II through IV, where numerous other surgical options have been suggested, of which many are effective [5, 8, 13, 14, 25-27].

\section{Validation}

To our knowledge, the validity and reliability of the Johnson and Strom classification have not been studied. Reliability here would refer to the ability of a classification to persistently classify a specific stage among reviewers (interobserver reliability) and by the same reviewer along different intervals (intraobserver reliability). Validity in this setting represents the ability to accurately associate physical examination with the radiographic and pathologic findings in each stage.

Grading a patient according to this classification system requires history, physical examination, and radiographic evaluation. As such, it can be impractical to have different observers evaluate the same patient to assess the system's 
Table 2. Classification system of Bluman et al.

\begin{tabular}{|c|c|c|c|}
\hline Stage & Clinical findings & Imaging & Treatment \\
\hline \multicolumn{4}{|l|}{ I } \\
\hline A & $\begin{array}{l}\text { Tenderness along posterior tibial tendon, } \\
\text { normal anatomy }\end{array}$ & Normal & Immobilization, orthosis, NSAIDs, tenosynovectomy \\
\hline $\mathrm{B}$ & $\begin{array}{l}\text { Tenderness along posterior tibial tendon, } \\
\text { normal anatomy }\end{array}$ & Normal & \\
\hline $\mathrm{C}$ & Slight hindfoot valgus, normal anatomy & Slight hindfoot valgus & \\
\hline \multicolumn{4}{|l|}{ II } \\
\hline A1 & $\begin{array}{l}\text { Supple hindfoot valgus, flexible forefoot } \\
\text { varus }\end{array}$ & $\begin{array}{l}\text { Hindfoot valgus } \\
\text { Meary's line disrupted } \\
\text { Loss of calcaneal pitch }\end{array}$ & $\begin{array}{l}\text { Orthosis, medial displacement calcaneal osteotomy, } \\
\text { tendoAchilles lengthening or Strayer procedure and flexor } \\
\text { digitorum longus transfer if deformity corrects only with } \\
\text { ankle plantar flexion }\end{array}$ \\
\hline A2 & $\begin{array}{l}\text { Supple hindfoot valgus, fixed forefoot } \\
\text { varus }\end{array}$ & & $\begin{array}{l}\text { Orthosis, medial displacement calcaneal osteotomy, flexor } \\
\text { digitorum longus transfer, cotton osteotomy }\end{array}$ \\
\hline $\mathrm{B}$ & $\mathrm{A} 2+$ forefoot abduction & $\begin{array}{l}\text { Talonavicular uncovering, } \\
\text { forefoot abduction }\end{array}$ & $\begin{array}{l}\text { Orthosis, medial displacement calcaneal osteotomy, flexor } \\
\text { digitorum longus transfer, lateral column lengthening }\end{array}$ \\
\hline $\mathrm{C}$ & $\begin{array}{l}\text { B }+ \text { medial column instability, first ray } \\
\text { dorsiflexion with hindfoot correction, } \\
\text { sinus tarsi pain }\end{array}$ & $\begin{array}{l}\text { First tarsometatarsal plantar } \\
\text { gapping }\end{array}$ & $\begin{array}{l}\text { Medial displacement calcaneal osteotomy, flexor digitorum } \\
\text { longus transfer, cotton osteotomy or medial column fusion }\end{array}$ \\
\hline \multicolumn{4}{|l|}{ III } \\
\hline A & Rigid hindfoot valgus, pain in sinus tarsi & $\begin{array}{l}\text { Subtalar joint space loss, } \\
\text { angle of Gissane sclerosis, } \\
\text { hindfoot valgus }\end{array}$ & Triple arthrodesis or custom bracing if not surgical candidate \\
\hline $\mathrm{B}$ & A + forefoot abduction & A + forefoot abduction & A+ lateral column lengthening \\
\hline \multicolumn{4}{|l|}{ IV } \\
\hline A & Supple ankle valgus & Hindfoot and ankle valgus & Surgery to have a plantigrade foot + deltoid reconstruction \\
\hline B & Rigid ankle valgus & & Tibiotalocalcaneal fusion \\
\hline
\end{tabular}

Table 3. Classification system of Raikin et al.

\begin{tabular}{|c|c|c|c|}
\hline Stage & Hindfoot & Mid-foot & Ankle \\
\hline Ia & Posterior tibial tendon tenosynovitis & Neutral alignment & Neutral alignment \\
\hline $\mathrm{Ib}$ & Posterior tibial tendon tendinitis without deformity & $\begin{array}{l}\text { Mild flexible mid-foot } \\
\text { supination }\end{array}$ & Mild valgus $<5^{\circ}$ \\
\hline IIa & $\begin{array}{l}\text { Flexible planovalgus }\left(<40 \% \text { talar uncoverage, }<30^{\circ}\right. \\
\left.\text { Meary's angle, incongruency angle } 20^{\circ}-45^{\circ}\right)\end{array}$ & $\begin{array}{l}\text { Mid-foot supination without } \\
\text { radiographic instability }\end{array}$ & Valgus with deltoid insufficiency \\
\hline $\mathrm{IIb}$ & $\begin{array}{l}\text { Flexible planovalgus }\left(>40 \% \text { talar uncoverage, }>30^{\circ}\right. \\
\text { Meary angle, incongruency angle }>45^{\circ} \text { ) }\end{array}$ & $\begin{array}{l}\text { Mid-foot supination with } \\
\text { instability }\end{array}$ & $\begin{array}{l}\text { Valgus with deltoid insufficiency and tibiotalar } \\
\text { arthritis }\end{array}$ \\
\hline IIIa & $\begin{array}{l}\text { Fixed planovalgus }\left(<40 \% \text { talar uncoverage, }<30^{\circ}\right. \\
\left.\text { Meary's angle, incongruency angle } 20^{\circ}-45^{\circ}\right)\end{array}$ & $\begin{array}{l}\text { Arthritic changes isolated to } \\
\text { medial column }\end{array}$ & $\begin{array}{l}\text { Valgus secondary to bone loss in lateral ankle } \\
\text { compartment (deltoid normal) }\end{array}$ \\
\hline IIIb & $\begin{array}{l}\text { Fixed planovalgus ( }>40 \% \text { talar uncoverage, }>30^{\circ} \\
\text { Meary's angle, incongruency angle }>45^{\circ} \text { ) }\end{array}$ & $\begin{array}{l}\text { Medial and middle-column } \\
\text { mid-foot arthritic changes }\end{array}$ & $\begin{array}{l}\text { Valgus secondary to bone loss in lateral ankle } \\
\text { compartment and deltoid insufficiency }\end{array}$ \\
\hline
\end{tabular}

interobserver reliability. In addition, the condition can evolve with time, making measurement of intraobserver reliability impossible. In addition, to confirm validity of this system, pathologic specimens might be required. This might be impractical because many patients will be treated conservatively and will not undergo surgery. Accordingly, validation of the Johnson and Strom classification has been difficult. Despite the inherent limitations of using a system that has not been validated, advancement of technology allowing better understanding of the deformity, and availability of more-complex and more-detailed classification systems, the Johnson and Strom classification persists widely, which may indicate the value to this system to users $[4,5,8,9,12,13,24,26,27]$.

\section{Limitations}

The main limitation of the Johnson and Strom classification system for adult-acquired flatfoot deformity is its failure to 
include all anatomic aspects of the pes planus deformity; by focusing on the role of the posterior tibial tendon, this system misses the importance of the spring ligament, deltoid ligament, naviculocuneiform joint, and tarsometatarsal joints, all of which have been shown to be involved, as have the hindfoot and forefoot in the deformity [8, 9, 12, 21, 22]. As a result, numerous authors $[5,9,20,24,27]$ have expanded the original classification system in an attempt to include the various structures involved. In addition, in a given stage in the Johnson and Strom classification, there may be important variations, and deformities do not necessarily progress in a linear or inevitable way.

To try to address this issue, Bluman et al. [5], in 2007, proposed a more comprehensive classification system that maintained the backbone Stages I through IV but added more subgroups to cover the wide spectrum of presentations in each stage (Table 2). Their major contribution was expansion of Stage II. According to the senior author's (MMS) experience, multiple deformities are present in Stage II at various degrees. Hindfoot valgus, forefoot abduction, and varus in addition to first ray instability were present, and accordingly, Bluman et al. [5] proposed a myriad of treatment options for each subset of patients.

Raikin et al. [27] proposed a newer complex classification system in 2012. The rationale behind their work was that previous classifications did not take in consideration involvement of the mid-foot (Table 3). As a result, their classification was based on anatomic location including the ankle, hindfoot, and mid-foot, with subgroups based on characteristic clinical and radiographic findings. Consequently, they suggested a treatment algorithm that fits each patient individually.

Although these classifications have addressed some of the concerns associated with the Johnson and Strom classification, these newer and yet-more-complex classifications have not been validated either. This lack of validation has to be considered when evaluating any research studies on flatfoot deformity. The lack of proof that these systems possess a high degree of interobserver and intraobserver reliability means that readers need to use them with great care. To the degree that one observer may classify a patient as having Stage II posterior tibial tendon dysfunction, and another observer may perceive the same patient to have a Stage III deformity, important differences in care could result. The same problem might arise when a reader wishes to interpret research using these systems, and apply that work in his or her practice.

\section{Conclusions}

The Johnson and Strom classification [17] describes the various stages associated with adult-acquired flatfoot deformity. It is composed of clinical, radiographic, and pathologic findings that correlate with the natural progression of the deformity, and it helps guide our understanding of the disease process. Despite the limitations associated with the classification, it remains widely used and accepted among foot and ankle surgeons, and is the most-commonly cited classification for research on adult-acquired flatfoot deformity.

\section{References}

1. Bare AA, Haddad SL. Tenosynovitis of the posterior tibial tendon. Foot Ankle Clin. 2001;6: 37-66.

2. Beals TC, Pomeroy GC, Manoli A 2nd. Posterior tendon insufficiency: diagnosis and treatment. J Am Acad Orthop Surg. 1999;7:112-118.

3. Benthien RA, Parks BG, Guyton GP, Schon LC. Lateral column calcaneal lengthening, flexor digitorum longus transfer, and opening wedge medial cuneiform osteotomy for flexible flatfoot: a biomechanical study. Foot Ankle Int. 2007;28:70-77.

4. Bluman EM, Myerson MS. Stage IV posterior tibial tendon rupture. Foot Ankle Clin. 2007;12:341-362, viii.

5. Bluman EM, Title CI, Myerson MS. Posterior tibial tendon rupture: a refined classification system. Foot Ankle Clin. 2007;12:233-249, v.

6. Brodsky JW, Baum BS, Pollo FE, Shabat S. Surgical reconstruction of posterior tibial tendon tear in adolescents: report of two cases and review of the literature. Foot Ankle Int. 2005;26:218-223.

7. Coetzee JC, Castro MD. The indications and biomechanical rationale for various hindfoot procedures in the treatment of posterior tibialis tendon dysfunction. Foot Ankle Clin. 2003;8:453-459.

8. Deland JT. The adult acquired flatfoot and spring ligament complex: pathology and implications for treatment. Foot Ankle Clin. 2001;6:129-135, vii.

9. Deland JT, Arnoczky SP, Thompson FM. Adult acquired flatfoot deformity at the talonavicular joint: reconstruction of the spring ligament in an in vitro model. Foot Ankle. 1992;13:327-332.

10. Ellis SJ, Yu JC, Williams BR, Lee C, Chiu YL, Deland JT. New radiographic parameters assessing forefoot abduction in the adult acquired flatfoot deformity. Foot Ankle Int. 2009;30:1168-1176.

11. Funk DA, Cass JR, Johnson K. Acquired adult flat foot secondary to posterior tibial-tendon pathology. J Bone Joint Surg Am. 1986;68:95-102.

12. Gazdag AR, Cracchiolo A 3rd. Rupture of the posterior tibial tendon: evaluation of injury of the spring ligament and clinical assessment of tendon transfer and ligament repair. $J$ Bone Joint Surg Am. 1997;79:675-681.

13. Haddad SL, Myerson MS, Younger A, Anderson RB, Davis WH, Manoli A 2nd. Symposium: adult acquired flatfoot deformity. Foot Ankle Int. 2011:32; 95-111.

14. Hadfield MH, Snyder JW, Liacouras PC, Owen JR, Wayne JS, Adelaar RS. Effects of medializing calcaneal osteotomy on Achilles tendon lengthening and plantar foot pressures. Foot Ankle Int. 2003;24:523-529.

15. Hill K, Saar W, Lee T, Berlet GC. Stage II flatfoot: what fails and why. Foot Ankle Clin. 2003;8:91-104.

16. 16. Johnson KA. Tibialis posterior tendon rupture. Clin Orthop Relat Res. 1983;177:140-147.

17. Johnson KA, Strom DE. Tibialis posterior tendon dysfunction. Clin Orthop Relat Res. 1989; 239:196-206.

18. Kulowski J. Tenovaginitis (tenosynovitis): general discussion and report of one case involving the posterior tibial tendon. $J$ Missouri State Med Assoc. 1936; 33:135-137. 
19. Mann RA, Thompson FM. Rupture of the posterior tibial tendon causing flatfoot: surgical treatment. J Bone Joint Surg Am. 1985;67:556-561.

20. Mankey MG. A classification of severity with an analysis of causative problems related to the type of treatment. Foot Ankle Clin. 2003;8:461-471.

21. McCormack AP, Ching RP, Sangeorzan BJ. Biomechanics of procedures used in adult flatfoot deformity. Foot Ankle Clin. 2001;6:15-23, v.

22. McCormack AP, Niki H, Kiser P, Tencer AF, Sangeorzan BJ. Two reconstructive techniques for flatfoot deformity comparing contact characteristics of the hindfoot joints. Foot Ankle Int. 1998;19:452461.
23. Mueller TJ. Ruptures and lacerations of the tibialis posterior tendon. J Am Podiatr Med Assoc. 1984;74:109-119.

24. Myerson MS. Adult acquired flatfoot deformity: treatment of dysfunction of the posterior tibial tendon. Instr Course Lect. 1997;46:393-405.

25. Parsons S, Naim S, Richards PJ, McBride D. Correction and prevention of deformity in type II tibialis posterior dysfunction. Clin Orthop Relat Res. 2010;468:1025-1032.

26. Pinney SJ, Lin SS. Current concept review: acquired adult flatfoot deformity. Foot Ankle Int. 2006;27:66-75.

27. Raikin SM, Winters BS, Daniel JN. The RAM classification: a novel, systematic approach to the adult-acquired flatfoot. Foot Ankle Clin. 2012;17:169-181. 